\title{
Lipid profile of pediatric patients with chronic rheumatic diseases - a retrospective analysis
}

\author{
(D) Wellington Douglas Rocha Rodrigues ${ }^{1}$ \\ (iD Roseli Oselka Saccardo Sarni ${ }^{2}$ \\ (D) Thais Tobaruela Ortiz Abad' \\ (iD) Simone Guerra Lopes da Silva ${ }^{1}$ \\ (iD) Fabiola Isabel Suano de Souza ${ }^{3}$ \\ (iD) Claudio Arnaldo Len ${ }^{4}$ \\ (D) Maria Teresa Terreri ${ }^{4}$
}

\begin{abstract}
1. Nutricionista, Doutor, Departamento de Pediatria, Universidade Federal de São Paulo, São Paulo, SP, Brasil. 2. Médica assistente e pesquisadora associada, Universidade Federal de São Paulo, São Paulo, SP, Brasil. 3. Médica, Professora assistente, Departamento de Pediatria, Universidade Federal de São Paulo, São Paulo, SP, Brasil. 4. Médico, Professor associado, Departamento de Pediatria, Universidade Federal de São Paulo, São Paulo, SP, Brasil.
\end{abstract}

http://dx.doi.org/10.1590/1806-9282.66.8.1093

\section{SUMMARY}

AIM: To describe the prevalence of dyslipidemia in children and adolescents with autoimmune rheumatic diseases (ARDs), particularly juvenile idiopathic arthritis (JIA), juvenile systemic lupus erythematosus (jSLE), and juvenile dermatomyositis (JDM).

METHODS: Retrospective cross-sectional study conducted in the pediatric rheumatology outpatient clinic. We evaluated 186 children and adolescents between the ages of 5 and 19 years. The medical records were reviewed for the following data: demographic and clinical features, disease activity, and lipid profile (triglycerides (TG), total cholesterol (TC), low density lipoprotein (LDL-C), high density lipoprotein (HDL-C) and very low density lipoprotein (VLDL-C)). In addition, non-HDL cholesterol was calculated as TC minus HDL-C. The cut-off points proposed by the American Academy of Pediatrics were used to classify the lipid profile.

RESULTS: Dyslipidemia was observed in 128 patients (68.8\%), the most common being decreased HDL-C (74 patients, 39.8\%). In the JIA group there was an association between the systemic subtype and altered LDL-C and NHDL-C, which demonstrated a more atherogenic profile in this subtype ( $p=0.027$ and $p=0.017$, respectively). Among patients with $j S L E$, the cumulative corticosteroid dose was associated with an increase in LDL-C ( $p=0.013)$ and with a decrease in HDL-C $(p=0.022)$.

CONCLUSION: Dyslipidemia is common in children and adolescents with ARDs, especially JIA, jSLE, and JDM, and the main alteration in the lipid profile of these patients was decreased HDL-C.

KEYWORDS: Juvenile idiopathic arthritis; Juvenile systemic lupus erythematosus; Juvenile dermatomyositis; Dyslipidemia

\section{INTRODUCTION}

Cardiovascular diseases (CVDs) are highly prevalent and a serious public health problem in the general population. ${ }^{1}$
Evidence points to an association between autoimmune rheumatic diseases (ARDs) and increased risk of CVD. ${ }^{1,2}$ The prevalence of acute myocardial infarction

DATE OF SUBMISSION: 25-Mar-2020

DATE OF ACCEPTANCE: 17-May-2020

CORRESPONDING AUTHOR: Maria Teresa Terreri

Rua Borges Lagoa, 802, Vila Clementino, SP, Brasil - 04038-001

Tel: +55 115574-7627

E-mail: teterreri@terra.com.br 
is approximately 50 times higher in women with systemic lupus erythematosus (SLE) than in those without the disease. ${ }^{2}$ In relation to the pediatric population, a study evaluating the impact of juvenile SLE (jSLE) on cardiovascular risk demonstrated not only an incidence of infarction similar to that seen in adult onset SLE patients but also that the first event occurred much earlier (at 32 years of age on average). ${ }^{3}$

A recent study showed that adults with juvenile idiopathic arthritis (JIA) were five times more likely to have metabolic syndrome and consequent cardiovascular risk than healthy individuals. ${ }^{4}$ A study evaluating adults with juvenile dermatomyositis (JDM) for 29 years showed changes in biomarkers and imaging exams associated with risk of CVD. ${ }^{5}$

Thus, with the increase in survival rates and the advancement in the treatment of ARDs, a new challenge arises: the identification of and early approach to risk factors for CVD.

In addition to the classic risk factors for the development of CVD, there are other triggers for ARD, such as chronic inflammatory processes and adverse events resulting from the therapy.

Our group has previously reported a high prevalence of dyslipidemia in children and adolescents with JIA and jSLE. ${ }^{6-9}$ It is well established in the literature that dyslipidemia is a relevant factor for triggering the atherosclerotic process. ${ }^{1}$ To our knowledge, this is the first study conducted in the pediatric population that describes the prevalence of dyslipidemia in individuals with JDM.

Therefore, the aim of this study was to describe the prevalence of dyslipidemia in children and adolescents with ARD, in particular JIA, jSLE and JDM.

\section{METHODS}

This was a retrospective cross-sectional study conducted in the pediatric rheumatology outpatient clinic. It involved 186 children and adolescents between five and 19 years of age with a diagnoses of JIA, jSLE, and JDM, according to the criteria of the International League of Association for Rheumatology (ILAR), the American College of Rheumatology (ACR), and the criteria of Bohan and Peter, respectively. ${ }^{10-12}$

Patients with any clinical manifestations and degree of disease activity, and having the disease for at least six months were included. Exclusion criteria were as follows: patients taking statins, pregnant women, patients with endocrine disorders, such as hypothyroidism, and with other autoimmune diseases or overlap syndrome. The medical records were reviewed for the following data: demographic and clinical features, disease activity, and lipid profile (triglycerides (TG), total cholesterol (TC), low density lipoprotein (LDL-C), high density lipoprotein (HDL-C), and very low density lipoprotein (VLDL-C)). Non-HDL cholesterol (NHDL-C) was also calculated as TC minus HDL-C. The cut-off points proposed by the American Academy of Pediatrics were used to classify the lipid profile. $^{13}$

Wallace criteria were used to evaluate the activity of JIA. ${ }^{14}$ The Systemic Lupus Erythematosus Disease Activity Index 2000 (SLEDAI-2K) ${ }^{15}$ and the Systemic Lupus International Collaborating/ACR Damage Index (SLICC-ACR/DI) ${ }^{16}$ were used to evaluate the activity of jSLE and irreversible cumulative damage. The activity of JDM was assessed considering the presence of skin alterations, muscle weakness, and increased levels of muscle enzymes.

SPSS software, version 20.0, was used to perform the statistical analysis. The categorical variables were expressed as frequencies and percentages and the continuous variables were presented as medians and interquartile intervals. The upper quartile (UQ) was used in the statistical analysis and was different for each disease: JIA: age $\geq 14.8$ years, duration of progression $\geq 7.3$ years, body mass index $(\mathrm{BMI}) \geq$ 23.0, BMI-for-age Z-score (ZBMI) $\geq 1.6$, height-for-age Z-score (ZHAZ) $\geq 0.47$, erythrocyte sedimentation rate (ESR) $\geq 23.3$, C-reactive protein (CRP $\geq 5.9)$; jSLE: age $\geq$ 18.6 years, duration of progression $\geq 6.6$ years, $\mathrm{BMI} \geq$ 24.3, ZBMI $\geq 1.08$, ZHAZ $\geq-0.41$, ESR $\geq 29$, cumulative corticosteroid dose (CCD) $\geq 425.3 \mathrm{mg}$; and JDM: age $\geq 15.2$ years, duration of progression $\geq 7.6$ years, BMI $\geq 22.0$, ZBMI $\geq 0.73$, ZHAZ $\geq 0.29$, and CCD $\geq 258.2$ mg. Pearson's chi-square or Fisher's exact association tests were used for the qualitative variables, and logistic regression and Mann-Whitney test were used for the quantitative variables. The significance level was set at $p<0.05$.

\section{RESULTS}

Table 1 shows the demographic, clinical, and laboratory data of children and adolescents with JIA, jSLE, and JDM, as well as their nutritional status. There was a predominance of patients with the oligoarticular subtype of JIA. According to the nutritional status classification, 63 patients (33.9\%) were overweight/ 
TABLE 1. DEMOGRAPHIC, CLINICAL, AND LABORATORY FEATURES AND NUTRITIONAL STATUS OF CHILDREN AND ADOLESCENTS WITH JUVENILE IDIOPATHIC ARTHRITIS (JIA), JUVENILE SYSTEMIC LUPUS ERYTHEMATOSUS (JSLE), AND JUVENILE DERMATOMYOSITIS (JDM).

\begin{tabular}{|c|c|c|c|c|c|}
\hline & JIA $(N=96)$ & jSLE $(\mathrm{N}=62)$ & JDM (N=28) & Total $(\mathrm{N}=186)$ & $p$-value \\
\hline Female & $65(67.7)$ & $52(83.9)$ & $16(57.1)$ & $133(71.5)$ & - \\
\hline Age (years) & $11.7(5.1-19.0)$ & $16.6(5.2-19.0)$ & $13.1(5.2-19.0)$ & - & $<0.001$ \\
\hline Duration of progression (years) & $4.4(0.6-16.7)$ & $4.6(0.9-11.0)$ & $5.0(0.13-13.7)$ & - & 0.691 \\
\hline \multicolumn{6}{|l|}{ Disease subtype } \\
\hline Systemic N (\%) & $11(11.4)$ & - & - & - & - \\
\hline Polyarticular & $38(39.6)$ & - & - & - & - \\
\hline Oligoarticular & $47(49)$ & - & - & - & - \\
\hline $\mathrm{BMI}$ & $19.3(13.4-39.9)$ & $21.3(15.1-36.6)$ & $18.2(14.3-30.4)$ & - & 0.136 \\
\hline$\geq$ Upper quartile & $24(25.7)$ & $16(25.8)$ & $7(25)$ & $47(25.3)$ & - \\
\hline ZBMI & $0.57(-3.4-+4.35)$ & $0.28(-2.48-+3.07)$ & $0.3(-1.79-+2.46)$ & - & 0.365 \\
\hline ZHAZ & $-0.23(-3.56-+2.73)$ & $-1.08(-4.59-+1.05)$ & $-0.91(-2.39-+2.07)$ & - & 0.001 \\
\hline \multicolumn{6}{|l|}{ Nutritional status } \\
\hline Eutrophic & $59(61.5)$ & $42(67.7)$ & $22(78.6)$ & $123(67.2)$ & - \\
\hline Overweight & $22(22.9)$ & $11(17.8)$ & $4(14.3)$ & $37(19.9)$ & - \\
\hline Obese & $15(15.6)$ & $9(14.5)$ & $2(7.1)$ & $26(14)$ & - \\
\hline \multicolumn{6}{|l|}{ Status of disease activity } \\
\hline Active & $32(33.3)$ & - & $8(28.6)$ & $40(32.3)$ & - \\
\hline SLEDAI $\geq 4$ & - & $12(19.4)$ & - & - & - \\
\hline SLICC & - & $5(8.1)$ & - & - & - \\
\hline us-CRP & $1.8(0.04-138.5)$ & $2.67(0.06-47.7)$ & - & - & - \\
\hline$\geq$ Upper quartile & $22(22.9)$ & - & - & - & - \\
\hline ESR & $12(2-93)$ & $14.7(1-75)$ & - & - & 1 \\
\hline z Upper quartile & $22(22.9)$ & $16(25.8)$ & - & $38(23.9)$ & - \\
\hline Cumulative corticosteroid dose & - & $267.8(75-1212.8)$ & $138.9(32.3-572.6)$ & - & 1 \\
\hline \multicolumn{6}{|l|}{ Glucocorticoids } \\
\hline Yes & - & $33(53.2)$ & $9(32.1)$ & $42(46.7)$ & - \\
\hline \multicolumn{6}{|l|}{ Biologics } \\
\hline Yes & $22(22.9)$ & - & - & - & - \\
\hline \multicolumn{6}{|l|}{ Non-biologics } \\
\hline Yes & 63 (65.6) & $62(100)$ & 23 (82.1) & $148(79.6)$ & - \\
\hline
\end{tabular}

BMI: Body mass index; ZBMI: BMI-for-age Z-score; ZHAZ: height-for-age Z-score; SLEDAI: Systemic Lupus Erythematosus Disease Activity Index 2000; SLICC: Systemic Lupus International Collaborating/ACR Damage Index; us-CRP: ultrasensitive C-reactive protein; ERS: erythrocyte sedimentation rate

TABLE 2. LIPID PROFILE OF CHILDREN AND ADOLESCENTS WITH JUVENILE IDIOPATHIC ARTHRITIS (JIA), JUVENILE SYSTEMIC LUPUS ERYTHEMATOSUS (JSLE), AND JUVENILE DERMATOMYOSITIS (JDM).

\begin{tabular}{l|l|l|l|l|l} 
& JIA (N=96) & jSLE (N=62) & JDM (N=28) & Total (N=186) & $p$-value \\
\hline TC & $152.5(101-313)$ & $153.5(105-259)$ & $150(90-277)$ & - & 1 \\
\hline Borderline/High N (\%) & $27(28.1)$ & $20(32.3)$ & $6(21.4)$ & $53(28.5)$ & - \\
\hline LDL-C & $90(46-218)$ & $85(44-201)$ & $85(43.2-165)$ & - & 0.285 \\
\hline Borderline/High N (\%) & $20(20.8)$ & $10(16.1)$ & $7(25)$ & $37(19.9)$ & - \\
\hline HDL-C & $48.5(17-82)$ & $51(27-93)$ & $45(25-90)$ & - & 0.317 \\
\hline Borderline/Low N (\%) & $39(40.6)$ & $20(32.3)$ & $15(56.3)$ & $74(39.8)$ & - \\
\hline VLDL-C & $15(4.8-82)$ & $17(5-54)$ & $19.5(7-56)$ & - & 0.223 \\
\hline NHDL-C & $104(61-243)$ & $102(57-220)$ & $110(51-199)$ & - & 0.316 \\
\hline Borderline/High N (\%) & $28(29.2)$ & $12(19.4)$ & $11(39.3)$ & $51(27.9)$ & - \\
\hline TG & $74(31-271)$ & $86(45-270)$ & $97(35-279)$ & - & \\
\hline Borderline/High N (\%) & $33(34.4)$ & $24(38.7)$ & $14(50)$ & $71(38.2)$ & 0.74 \\
\hline Dyslipidemia N & $65(67.7)$ & $42(67.7)$ & $21(75)$ & $128(68.8)$ & - \\
\hline
\end{tabular}




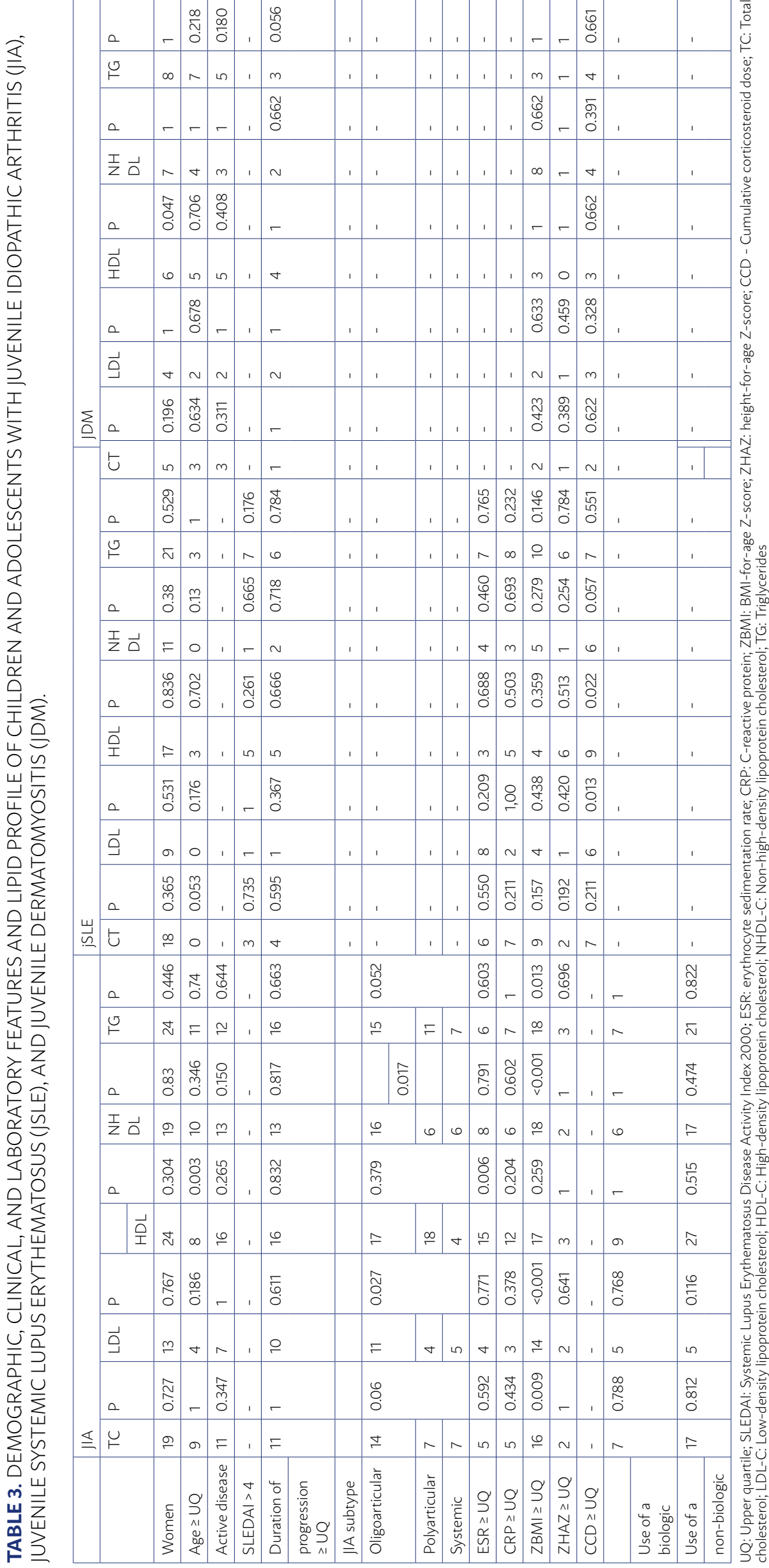


obese. We observed that ZHAZ was lower among the patients with jSLE than among the other two groups of patients.

Table 2 shows the lipid profile of children and adolescents with JIA, jSLE, and JDM. Dyslipidemia was present in 128 patients $(68.8 \%)$, the most common being decreased HDL-C (74 patients, 39.8\%). TG elevation was the most prevalent dyslipidemia in patients with jSLE and decreased HDL-C in patients with JIA and JDM. We did not detect significant differences in lipid profile between the three diseases.

Table 3 shows the associations of demographic, clinical, and laboratory data with the lipid profile of children and adolescents with JIA, jSLE, and JDM. In the JIA group there was an association between the systemic subtype and LDL-C and NHDL-C abnormalities, which demonstrated a more atherogenic profile in this subtype ( $\mathrm{p}=0.027$ and 0.017 , respectively). Logistic regression analysis showed that altered NHDL-C was associated with the JIA systemic subtype $(p=0.002)$ (data not shown). High levels of ESR were associated with decreased HDL-C ( $p=0.006)$. With regard to the nutritional status, patients with JIA who had ZBMI $\geq 1.6$ also had higher levels of TC $(p=0.009)$, LDL-c $(p<0.001)$, NHDL-c $(p<0.001)$, and TG $(p=0.013)$. Among the patients with jSLE, the CCD was associated with elevated LDL-C ( $\mathrm{p}=0.013)$ and decreased HDL-C $(\mathrm{p}=0.022)$.

\section{DISCUSSION}

This study showed a high frequency of dyslipidemia in children and adolescents with JIA, jSLE, and JDM. The most prevalent dyslipidemia was decreased HDL-C.

Studies evaluating lipid metabolism-related biochemical markers in children and adolescents with ARD are of great relevance ${ }^{6-9,17}$ and have focused on patients with JIA and jSLE. To our knowledge, there are no studies assessing the frequency of dyslipidemia in the population with JDM, and this work is therefore the first on this topic.

The pathophysiological mechanisms involved in the origin of dyslipidemia and risk of CVD in ARD have not yet been fully elucidated. However, some studies ${ }^{18-20}$ have shown that these diseases are associated with chronic inflammatory processes with elevated proinflammatory cytokines and also with adverse events related to drug therapy. In addition, classical risk factors for CVD such as unhealthy eating habits and poor lifestyle choices are involved. 6, 21, 22
It has been previously reported that the prevalence of dyslipidemia in patients with ARD ranges from $46 \%$ to $85 \%{ }^{23,24}$ In our sample, the prevalence of dyslipidemia was $67.7 \%$ for JIA and jSLE and $75 \%$ for JDM.

Low HDL-C was the most frequently observed change among the cholesterol-carrying lipoproteins. Other studies that also evaluated the prevalence of dyslipidemia in childhood ARD have confirmed our findings. ${ }^{8,22}$

Little is known about the causes of low HDL in ARD. However, it is worth noting that, in the presence of systemic inflammation, protective HDL can be converted into dysfunctional or pro-inflammatory HDL. This means that there is a modification in the protein content of the HDL molecules-a modification that favors the loss of its anti-inflammatory, anti-atherogenic, and anti-thrombotic effects, in addition to the loss of its function in the reverse transport of cholesterol. ${ }^{25,26}$

The most atherogenic lipid profile was observed in patients with the systemic subtype of JIA, with high levels of LDL-C and NHDL-C. Moreover, these patients had lower levels of HDL-C in association with increased ESR. It is known that the systemic subtype is associated with higher intensity of inflammation and manifestations such as anemia and thrombocytosis.

Our findings showed that JIA patients with a higher ZBMI had higher concentrations of TC, LDLC, NHDL-C, and TG. In a study aiming to determine the prevalence of excess body mass and to investigate the influence of obesity on early subclinical changes in the cardiovascular system, Glowinska-Olszewska et al. ${ }^{27}$ showed that patients with JIA and obesity had higher values of TC and TG than both non-obese JIA patients and healthy controls. Thus, these findings corroborate our results regarding these changes.

In relation to jSLE, we observed an association between CCD and high levels of LDL-C and low levels of HDL-C. Our findings are in line with those reported by other authors. ${ }^{8,28}$

With regard to JDM, our results were similar to those obtained in patients with JIA and jSLE. There was a tendency for an association between the duration of disease progression and high concentrations of TG.

This study is the first to describe the prevalence of dyslipidemia in children and adolescents with JDM. However, it had some limitations, including its retrospective design and the absence of a control group. 


\section{CONCLUSION}

We concluded that dyslipidemia is frequent in children and adolescents with ARD, especially JIA, jSLE, and JDM. The main change in the lipid profile of these patients was decreased HDL-C. Therefore, regular monitoring of lipid metabolism- related biomarkers is of paramount importance in the planning of interventions to reduce the risk of CVD in this population.

\author{
Declaration of conflict of interest \\ Nothing to declare
}

\section{RESUMO}

OBJETIVO: Descrever a prevalência de dislipidemias em crianças e adolescentes com doenças reumáticas autoimunes (Drai), em particular artrite idiopática juvenil (AIJ), lúpus eritematoso sistêmico juvenil (Lesj) e dermatomiosite juvenil (DMJ).

MÉTODOS: Estudo transversal retrospectivo realizado no ambulatório de reumatologia pediátrica. Foram avaliados 186 crianças e adolescentes com idades entre 5 e 19 anos. Foram coletados dos prontuários dados demográficos, clínicos, atividade de doença e perfil lipídico (triglicérides (TG), colesterol total (CT) e frações LDL-c (low density lipoprotein); HDL-c (high density lipoprotein) e VLDL-c (very low density lipoprotein). Foi também calculada a fração não HDL do colesterol (CT-NHDL -c). Para classificação do perfil lipídico, foram adotados os pontos de corte propostos pela American Academy of Pediatrics.

RESULTADOS: A dislipidemia foi observada em 128 pacientes (68,8\%), sendo a mais comum a diminuição do HDL-c em 74 (39,8\%). No grupo All houve uma associação entre o subtipo sistêmico com alteração de LDL-c e NHDL-c, mostrando um perfil mais aterogênico neste subtipo ( $p=0,027$ e 0,017, respectivamente). Em relação aos pacientes com Lesj, podemos observar que a dose cumulativa de CTC teve associação com o aumento do $L D L-c(p=0,013)$ e com a diminuição do HDL-c $(p=0,022)$.

CONCLUSÃo: A dislipidemia é frequente em crianças e adolescentes com Drai, em especial, All, Lesj e DMJ, e a principal alteração no perfil lipídico desses pacientes foi a diminuição do HDL-c.

PALAVRAS-ChaVE: Artrite idiopática juvenil. Lúpus eritematoso sistêmico juvenil. Dermatomiosite juvenil. Dislipidemia.

\section{REFERENCES}

1. Faludi AA, Izar MCO, Saraiva JFK, Chacra APM, Bianco HT, Afiune AN, et al. Atualização da Diretriz Brasileira de Dislipidemias e Prevenção da Aterosclerose - 2017. Arq Bras Cardiol 2017:109:1-76.

2. Cadaval RAM, Martinez JE, Mazzolin MA, Barros RGT, Almeida FA. Avaliação do risco coronariano em mulheres com lúpus eritematoso sistêmico. Rev Bras Reumatol 2009;49:658-669.

3. Hersh AO, von Scheven E, Yazdany J, Panopalis P, Trupin L, Julian L, et al. Differences in Long-Term Disease Activity and Treatment of Adult Patients With Childhood- and Adult-Onset Systemic Lupus Erythematosus. Arthritis Rheum. 2009;61:13-20.

4. Sule $S$ and Kevin Fontaine K. Metabolic syndrome in adults with a history of juvenile arthritis. Open Access Rheumatology: Research and Reviews 2018:10 67-72.

5. Eimer MJ, Brickman WJ, Seshadri R, RamseyGoldman R, McPherson DD, Smulevitz B, et al. Clinical Status and Cardiovascular Risk Profile of Adults with a History of Juvenile Dermatomyositis. J Pediatr 2011;159:795-801.

6. Caetano MC, Ortiz TT, Terreri MT, Sarni RO, Silva SG, Souza FI, et al.. Inadequate dietary intake of children and adolescents with juvenile idiopathic arthritis and systemic lupus erythematosus. | Pediatr 2009;85:509-515.

7. Ortiz TT, Terreri MT, Caetano M, Souza FS, D'Almeida V, Sarni ROS et al. Dyslipidemia in pediatric systemic lupus erythematosus: The relationship with disease activity and plasma homocysteine and cysteine concentrations. Ann Nutr Metab 2013;63:77-82.

8. Machado D, Sarni ROS, Abad TTO, Silva SGL, Khazaal EJB, Hix S et al. Lipid profile among girls with systemic lupus erythematosus. Rheumatol Int 2017;37:43-48.

9. Silva SGL, Terreri MT, Abad TTO, Machado D, Fonseca FLA, Hix S et al. The effect of nutritional intervention on the lipid profile and dietary intake of adolescents with juvenile systemic lupus erythematosus: a randomized, controlled trial. Lupus 2018;27: 820-827.
10. Petty RE, Southwood TR, Manners P, Baum |, Glass DN, Goldenberg |, et al. International League of Associations for Rheumatology classification of juvenile idiopathic arthritis: second revision, Edmonton, 2001. | Rheumatol 2004;31:390-392.

11. Hochberg MC. Updating the American College of Rheumatology revised criteria for the classification of systemic lupus erythematosus. Arthritis Rheum 1997; 40:1725.

12. Bohan A, Peter JB. Polymiositis and dermatomyositis. N Engl J Med 1975; 292:344-347.

13. Articles S. Expert Panel on Integrated Guidelines for Cardiovascular Health and Risk Reduction in Children and Adolescents: Summary Report. Pediatrics. 2011;128:213-256

14. Wallace CA, Ruperto N, Giannini E. Childhood Arthritis and Rheumatology Research Alliance, Pediatric Rheumatology International Trials Organization, Pediatric Rheumatology Collaborative Study Group. Preliminary criteria for clinical remission for select categories of juvenile idiopathic arthritis. J Rheumatol 2004;31:2290-2294.

15. Gladman DD, Ibañez D, Urowitz MB. Systemic lupus erythematosus disease activity index 2000. J Rheumatol 2002;29:288-291.

16. Gladman DD, Ginzler E, Goldsmith C, Fortin P, Liang M, Sanchez-Guerrero |, et al. The development and initial validation of systemic lupus international collaborating clinics/American College of Rheumatology Damage Index for systemic lupus erythematosus. Arthritis Rheum 1996;39:363-369.

17. Pugliese $C$, van der Vinne RTA, Campos LMA, Guardieiro PR, Saviolli C, Bonf E et al. Juvenile idiopathic arthritis activity and function ability: deleterious effects in periodontal disease? Clin Rheumatol 2016;35:81-91.

18. Spinas E, Kritas SK, Sagginp A, Mobili A, Caraffa A, Antinolfp P, et al. Role of mast cells in atherosclerosis: a classical inflammatory disease. Int | Immunopathol Pharmacol 2014; 27:517-521. 
19. Libby P. Inflammation and cardiovascular disease mechanisms. Am J Clin Nutr 2006;83:456-460.

20. Libby P. Role of inflammation in atherosclerosis associated with rheumatoid arthritis. Am / Med 2008;121:S21-31.

21. Cheng $Y$, Chen $Y$, Sun $X$, Li $Y$, Huang $C$, Deng $H$ et al. Identification of potential serum biomarkers for rheumatoid arthritis by high-resolution quantitative proteomic analysis. Inflammation 2014; 37:1459-1467.

22. Marangoni RG, Hayata AL, Borba EF, Azevedo PM, Bonfa E, Schainberg GC. Decreased high-density lipoprotein cholesterol levels in polyarticular juvenile idiopathic arthritis. Clinics 2011;66:1549-1552.

23. Toms TE, Panoulas VF, Kitas GD. Dyslipidaemia in rheumatological autoimune diseases. Open Cardiovascular Med | 2011;5:64-75.

24. Ardoin SP, Sanborg C, Schanberg LE. Management of dyslipidemia in children and adolescents with systemic lupus erythematosus. Lupus 2007;16:618-626

25. Hong F, Xa L. Dysfuncional high-density lipoprotein. Curr Opin Endocrinol Diabetes Obes 2009;2:156-162.

26. Benatti FB, Miossi R, Passareli M, Nakandakare ER, Perandini L, Lima FR et al. The effects of exercise on lipid profile in systemic lupus erythematosus and healthy individuals: A randomized trial. Rheumatol Int 2015;35:61-69.

27. Głowińska-Olszewska B, Bossowski A, Dobreńko E, Hryniewicz A, Konstantynowicz J, Milewski R, et al. Subclinical Cardiovascular System Changes in Obese Patients with Juvenile Idiopathic Arthritis. Mediators of Inflammation 2013;:1-11.

28. Boros CA, Bradley T], Cheung MM, Bargman |M, Russell |L, McCrindle $\mathrm{BW}$, et al. Early determinants of atherosclerosis in paediatric systemic lupus erythematosus. Clin Exp Rheumatol 2011;29:575-581. 